\title{
Removal of COD and ammoniacal nitrogen by banana trunk fiber with chitosan adsorbent
}

\author{
Noorain Suhani a, Radin Maya Saphira Radin Mohamed a, Ab Aziz Abdul Latiff a, Nazlizan Nasir a, \\ Baharin Ahmad a, Adeleke Abdulrahman Oyekanmi a, Halizah Awang b, Zawawi Daud a, \\ a Centre of Advance Research for Integrated Solid Waste Management (CARISMA), Universiti Tun Hussein Onn Malaysia, 86400, UTHM, Batu \\ Pahat, Johor Bahru, Malaysia \\ ${ }^{b}$ Faculty of Technical and Vocational Education, Universiti Tun Hussein Onn Malaysia, 86400, UTHM, Batu Pahat, Johor Bahru, Malaysia \\ *Corresponding author: zawawi@uthm.edu.my
}

\section{Article history}

Received 16 June 2019

Revised 8 August 2019

Accepted 16 October 2019

Published Online 15 April 2020

\section{Graphical abstract}

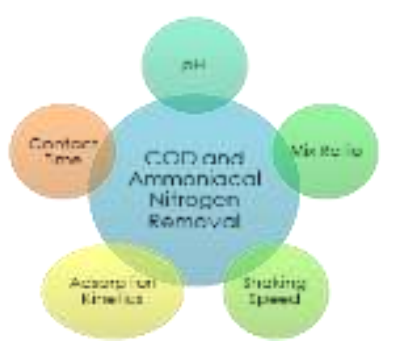

\begin{abstract}
Kitchen wastewater that is discharged to the environment is one of the contributing factors to water pollution in developing countries. Adsorption is one of the emerging technology of biological treatments that is an environmentally friendly for the removal of pollutants. Banana trunk fiber with chitosan as an adsorbent was investigated for minimizing COD and ammonia from the kitchen wastewater. The raw kitchen wastewater sample used in the study was collected from the Arked food court located in Universiti Tun Hussein Onn Malaysia in Johor (Malaysia). The optimum of ratio, pH, shaking speed and contact time for COD and ammonia removal were determined. The result indicated the optimum mix ratio of fiber with chitosan, $\mathrm{pH}$, shaking speed and contact time respectively was 50:50, pH 7, $125 \mathrm{rpm}$ and 120 minutes based on the adsorption of COD (87\%) and ammonia $(90 \%)$ by banana trunk fiber with chitosan. Kinetic study of the results gave a pseudosecond order the R2 was closed to unity which was 0.998 . It will significantly be considered for efficient removal of organic and nutrient pollutants present in kitchen wastewater treatment.
\end{abstract}

Keywords: Adsorption, ammonia, banana trunk fibers, chitosan

(c) 2020 Penerbit UTM Press. All rights reserved

\section{INTRODUCTION}

Water pollution is one of the most significant challenges to human health and environmental integrity in most parts of the world. As the world's population grows and prosperity spreads, water demands increase and multiply without the possibility supply increasing (Rafat, 2012). Malaysia has been progressing from an agricultural exporter to a major exporter of food and beverages, petroleum, textiles, clothing, palm oil, wood products and other industrial commodities. Wastewater generated from food operations has distinct characteristics that make it different from common municipal wastewater managed by public or private wastewater treatment plants as it is biodegradable and nontoxic, but it is well known for its high concentration of COD, BOD and suspended solid (Cristian, 2010; Silambarasan et al., 2012; Adeleke et al., 2017). The kitchen wastewater that is direct discharges to the drainage system without any sort of pre-treatment is mainly composed of contaminants such as fats, oil and grease (FOG) as well as a surfactant (dishwashing detergent). These contaminants could cause many detrimental environmental impacts, including fouling and clogging in the drainage and sewer system, thus it can generate unpleasant odors and treatment works which will eventually lead to decreased efficiency (Turunawarasu et al., 2013; Nasir et al., 2014).

Recently, crustaceans waste such as the shell of shrimp and crab have been utilized into a product name chitosan. Chitosan is derivative from $\mathrm{N}$-deacetylation of chitin, a second most abundant naturally occurring biopolymer next to cellulose. Chitosan exhibit unique characteristics such as hydrophilicity, biocompatibility, biodegradability, non-toxicity, adsorption properties, film-forming ability, bio-adhesively, poly-functionality (Wan Ngah et al., 2011; Nitapayat, 2014). It also contains high percentage of nitrogen compared to synthetically substituted cellulose. The uniqueness of chitosan can be considered as the answer to researcher's interest in developing cost-effective and environmentally friendly technologies for the remediation of soil and water polluted with toxic trace elements (Adarsh et al., 2014).

Banana trunk fiber is a lignocellulosic material; it consists of cellulose, hemicellulose, and lignin. The materials that contain cellulose (like bagasse, banana peel, banana trunk) can be used to treat organic or inorganic water pollutants in kitchen wastewater. Cellulose can be used as an adsorbent for the carboxyl and hydroxyl functional group which becomes the active binding site of the pollutant (Aliya et al., 2012) . Banana trunk fiber is an environmentally friendly, lowcost and renewable bioresource with porous structure. Adsorption of contaminants by banana trunk fiber has attracted great attention in recent years (Thilagan et al., 2013). Recently, banana trunk fiber has been used as a promising filler for the preparation of chitosan/banana trunk fiber composites.

In this study, banana trunk fiber with chitosan adsorbent were used to remove COD and ammonia from kitchen wastewater by batch adsorption process. The influences of mixing ratio, contact time, shaking speed and $\mathrm{pH}$ value of the adsorption efficiency were studied 
systemically. The treatment system is expected to effectively remove pollutants that present in the wastewater, thus making it suitable for reuse, especially for agricultural activities. The banana trunk fiber with chitosan was used for comparison. The removal performance by adsorbents was compared and analysed using the Pseudo-first order and Pseudo-second order kinetics models. The possible removal mechanisms were also discussed.

\section{EXPERIMENTAL}

\section{Kitchen wastewater sampling}

The kitchen wastewater sample was collected manually from the Arked's food court, University Tun Hussein Onn Malaysia (UTHM). Raw kitchen wastewater samples were collected from the Arked's effluent by using 20L HDPE ('high density polyethylene'). Once the kitchen wastewater samples arrived at the laboratory, the kitchen wastewater was stored at $4{ }^{\circ} \mathrm{C}$ in a cold room. All chemical analysis for the kitchen wastewater characterization was were performed within the following 24 hours in accordance with the Standard Methods for the Examination of Water and Wastewater by Federation WE, 2012.

\section{Preparation of adsorbent}

The banana trunks were collected from a plantation in Muar, Johor. Chitosan flakes with a deacetylation degree of $90 \%$ were acquired from Super Insi Enterprise, Kedah. Nodes of the raw banana trunk were first removed, and the remaining parts were cleaved in the longitudinal direction to thin slabs with $20-30 \mathrm{~cm}$ in length using a slicer. The banana trunk was cut into small pieces $(<2 \mathrm{~mm})$ before being washed with tap water to remove dust and dirt. The banana trunk was then sun dried and oven dried for 24 hours at $105^{\circ} \mathrm{c}$ until it achieved a constant weight (Phong et al., 2012). The dried banana trunk were grounded into powder for experimental uses.

\section{Optimum ratio}

The determination of the ratio between banana trunk fiber and chitosan adsorbent were based on the ammonia and COD removal. The experiment carried out in a series of $250 \mathrm{~mL}$ conical flask with varied amount of media ratio. In this study, $0.4 \mathrm{~g}, 1.2 \mathrm{~g}$, and $2 \mathrm{~g}$ of banana trunk fiber were added into $80 \mathrm{ml}$ of $5 \%$ acetic acid solution together with $3.6 \mathrm{~g}, 2.8 \mathrm{~g}$ and $2 \mathrm{~g}$ of chitosan, respectively, where the mixture represent 90:10, 70:30 and 50.50 for banana trunk fiber with chitosan. Then, the mixture processed into beads and tested its adsorption capacity by shaking speed. Subsequently, the optimum mix ratio between the combined two media was obtained by plotting the mix ratio against removal percentages.

\section{Characterization of adsorbent}

The chemical compositions of banana trunk fiber such as cellulose, hemicellulose and lignin content were analyzed by using TAPPI method, chlorination and Kurschner-Hoffner methods, respectively. Banana trunk fiber with chitosan would be tested using scanning electron microscopy (SEM) to analyze the morphological features and surface structure.

\section{Adsorption studies}

Adsorption experiments were carried out by using banana trunk fiber with chitosan composite samples as adsorbents. Batch adsorption experiments were carried out using a water bath shaker (Model RAPID). For a typical adsorption experiment, $5 \mathrm{~g}$ adsorbent was dispersed in $100 \mathrm{~mL}$ of raw kitchen wastewater without adjusting the $\mathrm{pH}$ value. The dispersion was stirred at a speed of $125 \mathrm{rpm}$ at $30^{\circ} \mathrm{C}$. The COD concentrations were assessed via the closed reflux titrimetric method (Mohamad et al., 1993) and ammoniacal nitrogen concentrations were determined by Nessler's method, using an ultraviolet visible spectrophotometer (Model HACH DR6000). For optimization the effect of $\mathrm{pH}$ on adsorption capacities was determined in the $\mathrm{pH}$ range from 2 to 10 . The $\mathrm{pH}$ was adjusted with $0.1 \mathrm{M} \mathrm{NaOH}$ or $0.1 \mathrm{M} \mathrm{HCl}$. The shaking speed in the range of $50-175 \mathrm{rpm}$ were used to examine the effect of shaking speed on adsorption of kitchen wastewater.

\section{Adsorption kinetics}

In order to investigate the adsorption of COD and ammonia on the surface of banana trunk fiber with chitosan, different kinetics models were applied to examine the controlling mechanism of adsorption process. In this study, pseudo-first order and pseudo-second order kinetic model were investigated to find the best fitted model for the experimental. The pseudo-first order kinetic model is expressed as Eq. (1) (Lagergren et al., 1898):

$$
\log \left(q_{e}-q_{t}\right)=\log q_{e}-\left(\frac{K_{\mathrm{i}} t}{2.303}\right)
$$

Where $\mathrm{q}_{\mathrm{t}}$ and $\mathrm{q}_{\mathrm{e}}$ are the amounts of ammonia nitrogen adsorbed at time $t$ and at equilibrium in $(\mathrm{mg} / \mathrm{g})$, respectively. $\mathrm{K}_{\mathrm{i}}$ is the pseudo-first order adsorption rate constant $\left(\mathrm{min}^{-1}\right)$. The slope and intercept of the plots of $\log \left(\mathrm{q}_{\mathrm{e}}-\mathrm{q}_{\mathrm{t}}\right)$ versus $\mathrm{t}$ were used to determine the rate constant $\left(\mathrm{K}_{\mathrm{i}}\right)$ and $\mathrm{q}_{\mathrm{e}}$. The pseudo-second order kinetic model is based on the assumption that chemisorption is the rate determining step and is given as Eq. (2) (Ho et al., 1998):

$$
\frac{t}{q_{t}}=\frac{1}{k_{2} q_{e}^{2}}+\frac{t}{q_{e}}
$$

Where $\mathrm{k}_{2}$ is the equilibrium rate constant of pseudo-second order adsorption $(\mathrm{g} / \mathrm{mg} \min )$. The values of $\mathrm{q}_{\mathrm{e}}$ and $\mathrm{k}_{2}$ were calculated from the slope and intercept of the linear plot of $t / q_{t}$ against $t$.

\section{RESULTS AND DISCUSSION}

\section{Characteristics of kitchen wastewater}

Numerous published studies describe the variations of kitchen wastewater quality from different food court. Table 1 presents the kitchen wastewater characteristics in comparison with Malaysia Standard refer to Standard B investigated in this study. The table suggests that kitchen wastewater has a high amount of COD and ammonia. The average values of COD and ammonia are 851 and $30.70 \mathrm{mg} / \mathrm{L}$, respectively. The results are also normalization of mixing ratio had been made to obtain a suitable working range of parameters for this study.

Table 1 Characteristics of kitchen wastewater obtained from Arked's food court, UTHM.

\begin{tabular}{ccc}
\hline Parameter & Average & $\begin{array}{c}\text { *Malaysia } \\
\text { Standard B }\end{array}$ \\
\hline COD (mg/L) & 851 & 200 \\
Ammonia Nitrogen (mg/L) & 30.70 & 20 \\
Suspended Solid (mg/L) & 363 & 100 \\
Color (Pt-Co) & 605 & 200 \\
Oil and Grease & 365 & 10 \\
pH & 5.96 & $5.5-9.0$ \\
\hline
\end{tabular}

\section{Chemical composition analysis}

The chemical composition analysis of banana trunk fiber and chitosan adsorbent are listed in Table 2 and Table 3. Chemical compositions in these samples such as cellulose, lignin and hemicelluloses were determined accordance with respective TAPPI standards method T 222 om-88 (lignin content). For cellulose and holocellulose, the methods were different, where cellulose content would be analysed by following Kurcnher-Hoffner method and chlorination method for determination of holocellulose in sample (Daud et al., 2014). From Table 2, it was found that banana trunk fiber contains high cellulose $(58.5 \%)$ content. Hemicellulose contents in banana trunk fiber is $15.4 \%$, respectively. Banana trunk fiber gives low lignin content with $13.2 \%$ compares to lignin in wood $(21 \%)$. Lower lignin content is normally found in nonwood fiber, function as adhesive to bind the cellulose in fiber and increase fiber strength and make it unbreakable (Tran, 2005). At the beginning of this study, one parameter was studied, with all the other parameters were kept constant. 
Table 2 Chemical composition of the banana trunk fibre.

\begin{tabular}{cc}
\hline Properties & Percentage (\%) \\
\hline Cellulose & 58.5 \\
Hemicellulose & 15.4 \\
Lignin & 13.2 \\
\hline
\end{tabular}

Table 3 Chemical composition of chitosan.

\begin{tabular}{cc}
\hline Properties & Specification \\
\hline Degree of deacetylation (\%) & $90-95$ \\
Ash content $(\%)$ & 1 \\
Moisture content $(\%)$ & 10 \\
Viscosity & $200-300 \mathrm{cps}$ \\
(1\% solution / 1\% acid) & \\
\hline
\end{tabular}

\section{Surface morphology studied}

Fig.1 shows the SEM image of the banana trunk fiber with chitosan beads. It can be seen that, the banana trunk fiber with chitosan bead is slightly rather rough due to the irregular stacking of the banana trunk fiber particles. The elemental mapping images also show that COD and ammoniacal nitrogen were found to be uniformly distributed along the surface of the beads. This result suggests that the adsorbent of banana trunk fiber with chitosan bead is governed by electrostatic forces and natural entrapment into the porous adsorbent (Nitayapat and Jintakosol, 2015).

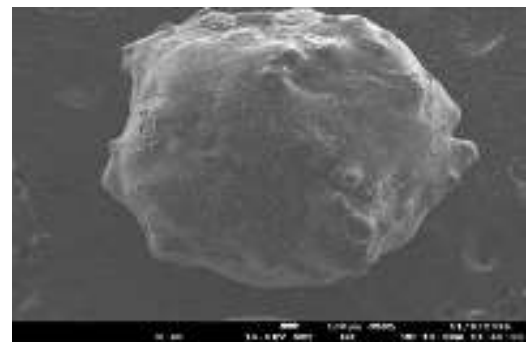

Fig. 1 Morphology of banana trunk fiber with chitosan.

\section{Effect of $\mathrm{pH}$}

Fig. 2 shows that the parameter removal were maximum at $\mathrm{pH} 7$ where the COD and ammonia removal by the banana trunk fiber with chitosan adsorbent was 84 and $86 \%$ respectively. Adsorption capacity was analyzed over a $\mathrm{pH}$ range between 2 to 10 . The removal efficiency was increased as the $\mathrm{pH}$ increased until it reached $\mathrm{pH} 7$, and it started to decrease slowly at $\mathrm{pH}$ 8. The low pollutant adsorption at lower $\mathrm{pH}$ values may be explained on the basis of active sites protonation, resulting in $\mathrm{H}^{+}$and cations competition to occupy binding sites (Saeed et al., 2005).

According to Huang et al. (2010), this behavior can be clarified by the fact that at $\mathrm{pH}$ values above 8 partial dissolution of the adsorbents occurs, and it is also likely that $\mathrm{NH}_{4}{ }^{+}$is converted into $\mathrm{NH}_{3}$ specimen. Although, at $\mathrm{pH}$ values below 8 , the $\mathrm{NH}_{4}{ }^{+}$ion concentration in solution rises when $\mathrm{pH}$ decreases which results in a decline towards removal efficiency, as the $\mathrm{H}^{+}$ion concentration subsequently rises with the decrease in $\mathrm{pH}$ and intensifies the competition for exchange sites.

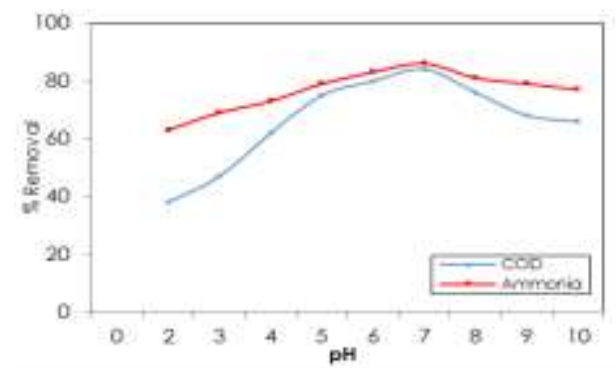

Fig. 2 Effects of $\mathrm{pH}$ on COD and ammonia removal.

\section{Media mix ratio}

The dosage added has a great influence on sorption process since the dose added into the solution determine the number of binding site for adsorption (Zafar et al., 2007). Fig.3 shows that ratio 50:50 of banana trunk fiber with chitosan adsorbent gives the maximum adsorption of the parameters was removed, with COD (68\%) and ammonia (62\%) removal, respectively. A study conducted by Ekmekyapar et al. (2006) explains that this situations occur because of the increasing of binding site mean availability to adsorb is higher and the decreasing of adsorption capacity may attributed to over lapping or aggregation of adsorption site resulting decrease in total adsorbent surface area. The optimum conditions are adequate at a ratio of 50:50 for COD and ammonia removal to show good adsorption behavior among other ratio. Considerably, the ratio achieves a significant replacement of the conventional media without detriment to pollutant removal.

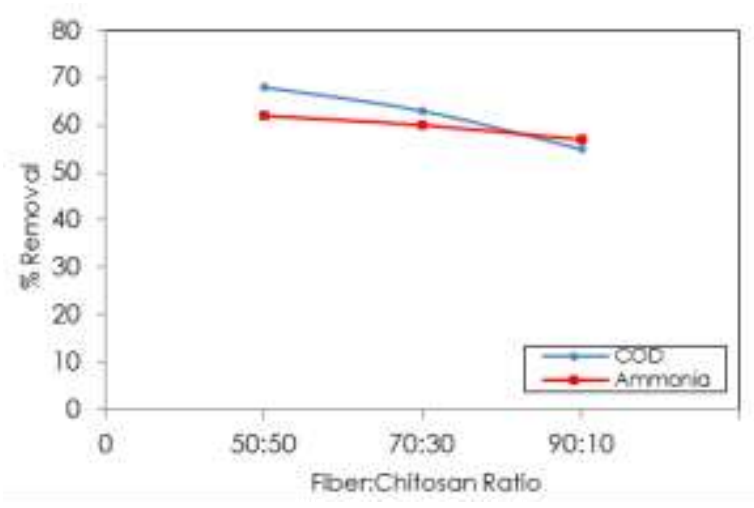

Fig. 3 Fiber:chitosan mix ratio.

\section{Effect of shaking speed}

Shaking speed is an important parameter in adsorption phenomena since it influences the distribution of the solute in the bulk solution and the rate of formation of the external boundary film (Rida et al., 2013). The effect of the shaking speed on COD and ammonia was conducted with varied speed from $50-175 \mathrm{rpm}$. From the Fig. 4, COD and ammonia removal show similar patterns with the decreasing of removal with the increasing of speed. The optimum removal of banana trunk fiber with chitosan adsorbent is at $125 \mathrm{rpm}$. The highest removal percentage of COD is $83 \%$ and ammonia is $80 \%$.

The increase in percentage of removal can be explained by the fact that increasing shaking speed reduced the film boundary layer surrounding of particles, thus increasing the external film transfer coefficient, and hence the percentage ammonia nitrogen removal (Ninda et al., 2009).

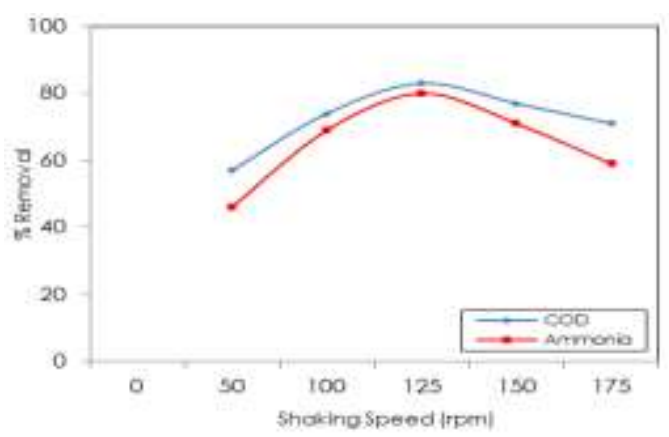

Fig. 4 Effects of shaking speed on COD and ammonia removal.

\section{Effect of contact time}

The effect of contact time on the removal of COD and ammonia are summarized in Fig.5. The result of COD and ammonia increase with the rise of the contact time up to time 2 hours in which the efficiency is 80 and $84 \%$, respectively. The pattern of removal showed that with the increasing of time, the removal of ferum also increasing 
until it reached saturated level where the reading became constant, which indicated equilibrium. This observation could be explained, as at the very beginning of the adsorption process, a large number of vacant surface sites were available for adsorption, which may be the reason for the rate of adsorption boosted in the initial stages. Then, after a lapse of some time, the remaining vacant surface sites were difficult to be occupied and beyond indicated contact time where it reached saturated level, the percentage of removal almost constant indicating the attainment of equilibrium conditions (Srivastava et al., 2006).

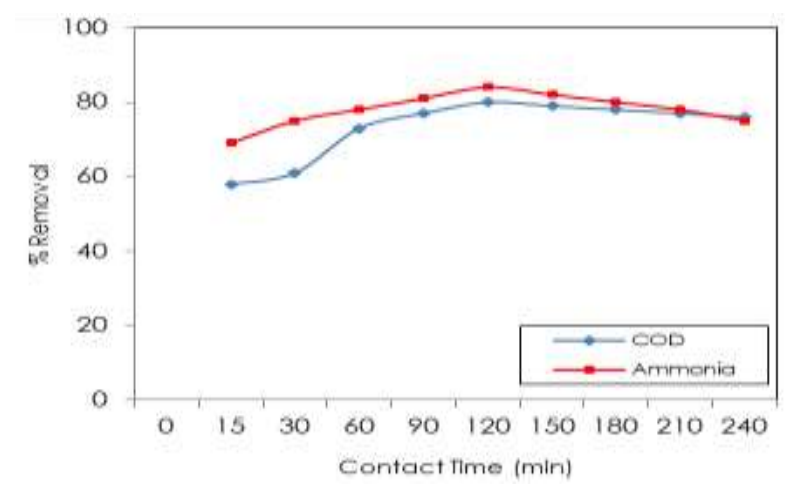

Fig.5 Effects of contact time on COD and ammonia removal.

\section{Adsorption kinetic}

Adsorption kinetics models were applied to the experimental data in order to analyze the rate of adsorption and possible adsorption mechanism of COD and ammonia onto banana trunk fiber with chitosan. From Table 4, can be observed that the pseudo-first-order equation did not provide a good fit to the experimental data whereby the amount of sorbed COD and ammonia at equilibrium $\left(\mathrm{q}_{\mathrm{e}}\right)$ for banana trunk fiber with chitosan was $11.46 \mathrm{mg} / \mathrm{g}$ and $0.5 \mathrm{mg} / \mathrm{g}$, which was almost same as the calculated value for pseudo-second order model which was $11.26 \mathrm{mg} / \mathrm{g}$ and $0.499 \mathrm{mg} / \mathrm{g}$. Besides, the $\mathrm{R}^{2}$ in pseudo-second-order model gave a value of 0.9982 (COD) and 0.9997 (ammonia) that indicated a better fit. On the other hand, the pseudofirst-order obtained the $\mathrm{R}^{2}$ value of 0.6783 and 0.6172 which was lower than the second order. Thus, this results showed that the adsorption of COD and ammonia obey the pseudo second-order model.

Table 4 Parameter of the Pseudo-first order and Pseudo-second order.

\begin{tabular}{ccccc}
\hline $\begin{array}{c}\text { Banana trunk } \\
\text { fiber with } \\
\text { chitosan }\end{array}$ & \multicolumn{5}{c}{ Pseudo-first order } \\
\cline { 2 - 5 }$(\mathbf{m g} / \mathbf{g})$ & $\boldsymbol{q e}$ & $\boldsymbol{K}_{\mathbf{2}}$ & $\boldsymbol{R}^{2}$ \\
\hline COD & 11.46 & 704.368 & 0.00002 & 0.6783 \\
Ammonia & 0.5 & 30.269 & 0.00001 & 0.6172 \\
\hline Banana trunk & \multicolumn{4}{c}{ Pseudo-second order } \\
\cline { 2 - 5 } fiber with & $\boldsymbol{q}_{\text {exp }}$ & $\boldsymbol{q e}$ & $\boldsymbol{K}_{\mathbf{2}}$ & $\boldsymbol{R}^{2}$ \\
chitosan & $(\mathbf{m g} / \mathbf{g})$ & & & \\
\hline COD & 11.46 & 11.26 & 0.0247 & 0.9982 \\
Ammonia & 0.5 & 0.499 & 1.2249 & 0.9997 \\
\hline
\end{tabular}

\section{CONCLUSION}

Banana trunk fiber with chitosan composites can be successfully used as an adsorbent for COD and ammoniacal nitrogen from kitchen wastewater. The results indicate that the mixing ratio for banana trunk fiber with chitosan composite in the treatment of COD and ammonia is $50: 50$ and that the optimum shaking speed of the mixed media is $125 \mathrm{rpm}, \mathrm{pH} 7$ in 2 hours contact time. This based on above optimal conditions that the maximum COD and ammoniacal nitrogen removal was $87 \%$ and $90 \%$. Thus, it can be defined that pseudo-first order kinetics might be insufficient to interpret COD and ammonia adsorption. The mixture of banana trunk fiber with chitosan composite, has the ability to be utilized as an adsorbent in pollutant removal from kitchen wastewater. The advantages of of using this mixture is it requires little dosage of adsorbent and reduction of the cost, which can be applied in the treatment. The research outcomes of this study contributed to the existing literature on alternative media for kitchen wastewater treatment, especially in developing countries. Further research conducted by UTHM is still in progress to determine other factors that may influence the field of study.

\section{ACKNOWLEDGEMENT}

The authors acknowledge the research grant provided by the Office for Research, Innovation, Commercialization and Consultancy Management (ORICC) of the Universiti Tun Hussein Onn Malaysia (UTHM) for the Fundamental Grant Scheme (FRGS Vot No. 1457).

\section{REFERENCES}

Adarsh, K. J., Madhu, G. 2014. A comparative study on metal adsorption properties of different forms of chitosan. Int. J. Innov. Res. Sci. Eng. 3, 2, 9609-9617.

Adeleke, A. O., Latiff, A. A. A., Al-Gheethi, A. A., Daud, Z. 2017. Optimization of operating parameters of novel composite adsorbent for organic pollutants removal from POME using response surface methodology. Chemosphere.174, 232-242.

Aliya, N. H., Fani, R., Driyanti, R. 2012. Banana peels and stem (musa x paradisiaca linn.) as biosorbent of copper in textile industry wastewater. Res. J. Pharm., Biol. Chem. Sci. 3, 3, 1171-1178.

Cristian. O. 2010. Characterization of the untreated wastewater produced by food industry. Analele Universității din Oradea, Fascicula: Protecția Mediului. 15, 709-714

Daud, Z., Hatta, M. Z. M., Kassim, A. S. M., Awang, H., Aripin, A. M. 2014 Exploring of agro waste (pineapple leaf, corn stalk, and napier grass) by chemical composition and morphology study. Bioresources. 9, 1, 872-880.

Ekmekyapar, F., Aslan, A., Bayhan, Y. K., Cakici, A. 2006. Biosorption of copper (II) by nonliving lichen biomass of cladonia rangiformis hoffm. $J$. Hazard. Mater. 137, 1, 293-298.

Federation W. E. 2012. Standard methods for the examination of water and wastewater. American Public Health Association (APHA). Washington, DC, USA.

Ho, Y. S., McKay, G. 1998. The kinetics of sorption of basic dyes from aqueous solution by sphagnum moss peat. Can. J. Chem. Eng. 76, 822827.

Huang, H., Xiao, X., Yan, B., Yang, L. 2010. Ammonium removal from aqueous solutions by using natural chinese (chende) zeolite as adsorbent. J. Hazard. Mater. 175, 247-252.

Lagergren. S. 1898. About the theory of so-called adsorption of soluble substances. K Sven Vetenskapsakad Handl. 24, 4, 1-39.

Mohamad, H. T., Teoh, C. H., Kamarudzaman, A., Ali, M. A. 1993. Zero burning an environmentally friendly replanting technique. Proceedings of the 1993 PORIM International Palm Oil Congress (PIPOC), 185-195.

Nandi, B. K., Goswami, A., Purkait, M. K. 2009. Adsorption characteristics of brilliant green dye on kaolin. J. Hazard. Mater. 161, 387-395.

Nasir, N., Daud, Z. 2014. Performance of aluminium sulphate and polyaluminium choloride in biodiesel wastewater. J. Mech. Eng. Sci. 7, 1189-1195.

Nitayaphat, W. 2014. Utilization of chitosan/bamboo charcoal composite as reactive dye adsorbent. Chiang Mai J. Sci. 41, 1, 174-183.

Nitayaphat, W., Jintakosol, T. 2015. Removal of silver(I) from aqueous solutions by chitosan/bamboo charcoal composite beads. J. Cleaner Prod. 87, 850-855.

Phong, N. T., Fujii, T., Chuong, B., Okubo, K. 2012. Study on how to effectively extract bamboo fibers from raw bamboo and wastewater treatment. J. Mater. Sci. Res. 1,1, 144-155.

Rafat. K. 2012. Greywater treatment for reuse by slow sand filtration: study of pathogenic microorganisms and phage survival. Chem Process Eng. (Version 1).

Rida, K., Bouraoui, S., Hadnine, S. 2013. Applied clay science adsorption of methylene blue from aqueous solution by kaolin and zeolite. Appl. Clay Sci. 83-84, 99-105.

Saeed, A., Akhter, M. W., Iqbal, M. 2005. Removal and recovery of heavy metals from aqueous solution using papaya wood as new biosorbent. Sep. Purif. Technol. 45, 25-31.

Silambarasan, T., Vikramathithan, M., Dhandapani, R., Mukesh, K. D. J., Kalaichelvan, P. T. 2012. Biological treatment of diary effluent by microalgae. World J. Sci.Technol. 2,7, 132-134. 
Srivastava, V. C., Mall, I. D., Mishra, I. M. 2006. Equilibrium modelling of single and binary adsorption of cadmium and nickel onto bagasse fly ash. Chem. Eng. J. 117, 1, 79-91.

Thilagan, J., Gopalakrishnan, S., Kannadasan, T. 2013. A study on adsorption of copper(II) ions in aqueous solution by chitosan reinforced by banana stem fibre. Int. J. Green. Herbal. Chem. 2, 2, 226-240.

Tran, A. V. 2005. Chemical analysis and pulping study of pineapple crown leaves. Ind. Crops Prod. 24, 66-74.

Turunawarasu, D., Zakaria, M., Zuliana, A. 2013. A novel and sustainable approach in treating restaurant wastewater with kapok fiber. Int. J. Chem. Environ. Eng. 4, 5, 273-280.

Wan Ngah, W. S., Teonga, L. C., Hanafiah, M. A. K. M. 2011. Adsorption of dyes and heavy metal ions by chitosan composites: a review. Carbohydr. Polym. 83, 1446-1456.

Zafar, M. N., Nadeem, R., Hanif, M. A. 2007. Biosorption of nickel from protonated rice bran. J. Hazard. Mater. 143, 1-2, 478-485. 